\title{
RELAÇÕES SOLOS - SUPERFICIES GEOMÓRFICAS NA PORÇÃO NORTE DA BACIA DO RIBEIRÃO CHIQUEIRO - GOUVEIA, MG
}

\author{
Alisson Duarte Diniz (*), Cristiane Valéria de Oliveira (**) \& Cristina H. R. R. Augustin (***)
}

\begin{abstract}
This article aimed reports the relationship between landform and soils in the northerly part of Ribeirão Chiqueiro basin, Gouveia, MG. The results showed that the region's soils are associated to the landforms and to the lithology. The Red Latosol is found on basic and metabasic rocks areas, in gentle undulating relief and undulating relief characterized by convex - convex and convex rectilinear slopes. The Red Yellow Latosol develops on granites, in undulating gentle landform, with convex rectilinear slopes, extensive and more homogeneous. The Cambisols are found in undulating forms, presenting short convex - convex slopes, in granite and schist areas. Concerning the Lithosols, steep slope, associated to the mountain relief and high altitude climate conditions, and even to the flat landform upon a lithology resistant to the weathering, provided a little development of these soils. Fluvial soils are associated to terrace areas, being characterized by little development.
\end{abstract}

\section{RESUMO}

\begin{abstract}
O objetivo desse artigo é de mostrar a relação entre as superfícies geomórficas e as classes de solos na porção norte da bacia do Ribeirão Chiqueiro, Gouveia (MG). O estudo e mapeamento dos solos da região demonstraram que os aspectos pedológicos estão fortemente associados às formas do relevo e a litologia. Os Latossolos Vermelhos encontram-se em áreas de rochas metabásicas, em relevo suave ondulado e ondulado com vertentes convexas retilíneas e convexo - convexas. Os Latossolos Vermelho - Amarelos estão em áreas de granito, em relevo suave ondulado e ondulado com vertentes convexas retilíneas extensas e mais homogêneas. Os Cambissolos estão localizados em relevo ondulado e forte ondulado, apresentando encostas convexo - convexas curtas, em áreas de granitos e xistos. Em relação aos Neossolos Litólicos, a forte declividade, associada ao relevo montanhoso e ao clima frio de altitude, e mesmo o relevo plano sobre uma litologia resistente ao intemperismo, proporcionaram o pouco desenvolvimento desses solos. Os Neossolos Flúvicos estão relacionados às regiões de terraços e são caracterizados por camadas intercaladas de areia grossa e areia fina.
\end{abstract}

\section{INTRODUÇÃO}

O estudo do recurso natural solo adquire importância cada vez maior nos meios acadêmicos do Brasil, visto que a sua degradação compromete o meio ambiente natural como um todo e, conseqüentemente, a economia e a qualidade de vida da população atingida. Neste contexto, os levantamentos pedológicos são um instrumento de grande importância no uso sustentável desse recurso, uma vez que fornecem informações sobre a natureza dos solos, suas propriedades morfológicas, químicas e físicas, sua distribuição geográfica e extensão territorial.

Para se realizar um levantamento pedológico é importante que se conheçam os aspectos geológicos, geomorfológicos, hidrológicos, climáticos e fitogeográficos da área a ser estudada, pois estes fatores são interdependentes. Assim, as características de um desses componentes interferem nas dos outros, ou, as mudanças em um deles podem ter várias repercussões no ambiente (Christian e Stewart, 1968). As características dos solos serão condicionadas, desta forma, pelos aspectos ambientais, assim como determinarão aspectos peculiares nas paisagens.

Em vista disto, em um mapeamento pedológico as características ambientais podem ser utilizadas para subdividir, ainda mais, as classes de solos, gerando mapas mais detalhados e mais próximos da realidade, $\mathrm{o}$ que facilita o planejamento do uso desse recurso. No mapa pedológico estas subdivisões são conhecidas como fases. No Brasil, as fases mais utilizadas são as indicadas pela vegetação primária, onde é possível estabelecer

\footnotetext{
* Mestre em Geografia e Análise Ambiental IGC-UFMG E-mail: alissondiniz@brfree.com.br e alissondiniz@yahoo.com.br ** Professora do Departamento de Geografia, IGC-UFMG E-mail: cristiane@geo.igc.ufmg.br. *** Professora do Departamento de Geografia, IGC-UFMG E-mail: chaugust@igc.ufmg.br.
} 
relações entre a vegetação e determinadas condições edafoclimáticas; e as de relevo, que qualificam condições de declividade, comprimento de encostas e configuração superficial dos terrenos, que afetam as formas de modelado de áreas de ocorrência das unidades de solo (EMBRAPA, 1999). Muitas pesquisas associam, portanto, os solos às condições do relevo como as de Ruhe (1975), Birkeland (1974) e Birkeland (1984).

No município de Gouveia-MG, os processos erosivos são acelerados, proporcionando a formação de grandes voçorocamentos e causando, dessa forma, grandes prejuízos à atividade econômica, principalmente a agropecuária. Várias foram as pesquisas realizadas, mas a região carecia de um levantamento pedológico mais detalhado. Neste sentido, os aspectos geomorfológicos foram de grande importância na explicação da pedogênese e variação espacial dos solos, o que contribui, também, para os avanços dos estudos no que se refere aos processos erosivos.

O objetivo desta pesquisa foi associar os solos mapeados às formas de relevo da porção norte da bacia do Ribeirão Chiqueiro, Gouveia, MG, destacando, essencialmente, como a forma da vertente ou da superfície geomorfológica é importante para os trabalhos de mapeamento pedológico e diferenciação dos solos de uma região.

\section{CARACTERÍSTICAS GERAIS DA ÁREA DE ESTUDO}

O município de Gouveia, no qual se encontra a bacia do Córrego do Chiqueiro, está localizado na grande unidade morfoestrutural denominada Serra do Espinhaço, na porção centro norte do Estado de Minas Gerais (Figura 1), distando cerca de $250 \mathrm{~km}$ ao norte de Belo Horizonte. Dentro dessa unidade, o município insere-se sobre as rochas granitóides, metassedimentares e metavulcânicas.
Segundo Augustin (1995) e Saadi e Valadão (1987), a bacia do córrego do Chiqueiro corresponde a uma depressão com sentido N-S, que se originou do intemperismo e da erosão local dos três grandes grupos litológicos: o Complexo Basal, o Supergrupo Rio Paraúna e os metassedimentos proterozóicos do Supergrupo Espinhaço, que conformavam um antigo anticlinório localizado na área.

De acordo com Almeida-Abreu (1985, 1989), a base geológica da área é formada pelo Complexo Basal ou Seqüência Infracrustal; Supergrupo Rio Paraúna, Supergrupo Espinhaço e pelas Rochas Metabásicas.

Segundo Augustin (1995), na bacia localizam-se os seguintes compartimentos geomorfológicos, determinados por níveis altimétricos:

- $\quad 1.300$ a 1.450 metros: é a primeira unidade e a de maior altitude, formada, basicamente, por rochas da Formação São João da Chapada (metarenitos) com colinas tabulares e cristas monoclinais.

- 1.200 a 1.300 metros: superfície tabular composta por ortoquartzitos da formação Galho do Miguel, finos, muito diaclasados e fraturados (metarenitos puros e finos).

- $\quad 1.100$ a 1.200 metros: a litologia predominante nesta unidade morfoestrutural são os xistos do Grupo Costa Sena.

- Entre 900 e 1.000 metros encontra-se a Depressão de Gouveia, que apresenta uma dissecação fluvial comandada pelos Ribeirões do Chiqueiro e da Areia. Ao longo do eixo principal da depressão aflora o embasamento arqueano representado pelos migmatitos e granitos da seqüência infracrustal (Complexo Basal).

O clima do município de Gouveia se caracteriza por apresentar duas estações bem definidas: uma seca (de maio a setembro), onde as temperaturas são baixas, e outra úmida (de agosto a abril) onde as temperaturas são mais altas. Segundo Nimer (1989), este clima corresponde ao do tipo CWb, mesotérmico de Koppen.

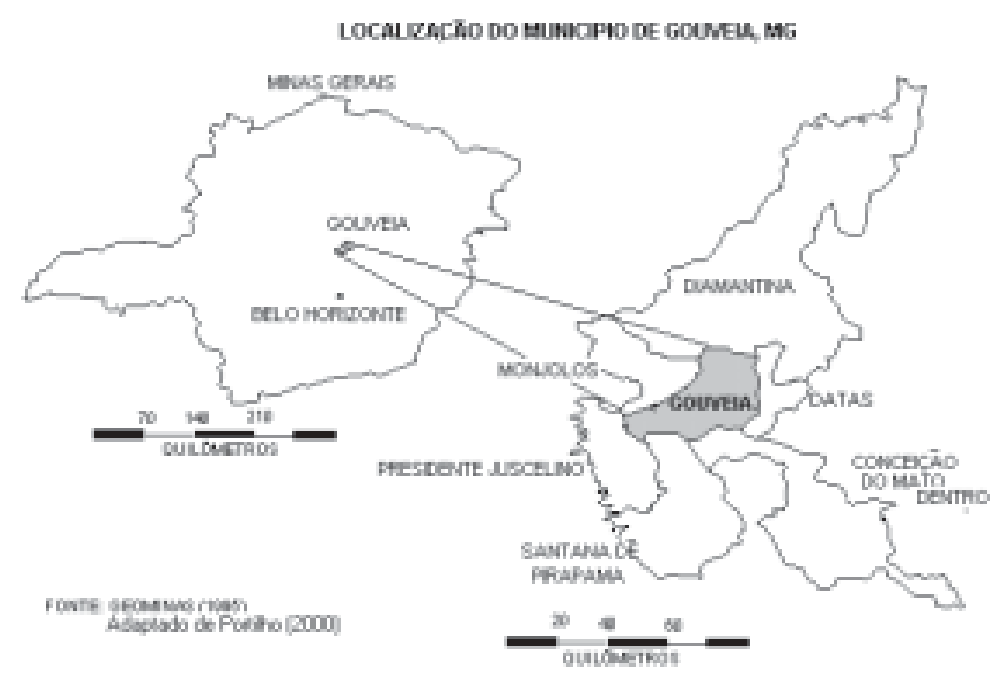

Figura 1: Localização do município de Gouveia no estado de Minas Gerais. FONTE: Portilho (2000). 


\section{METODOLOGIA}

A base da amostragem e, posteriormente, mapeamento das unidades dos solos, foi a fotointerpretação, utilizando-se conceitos e metodologias desenvolvidos por Vink (1968), Komarov (1968), Christian e Stewart (1968) e Wright (1972, 1973). As bases de referência utilizadas foram as fotografias aéreas, na escala de 1:25.000 (vôo Cruzeiro do Sul, DNPM/CPRM de 1979), mapas topográficos (IBGE, 1986) e geológicos (Almeida-Abreu, 1985; COMIG e UFMG, 1996) na escala de 1:100.000.

Inicialmente identificou-se forma de topos, encostas, vales, litologias, hidrografia, erosão e outras informações como a vegetação, áreas construídas e estradas. A interpretação das fotografias aéreas foi realizada tendo como referência às variações de textura e tons de cinzas na foto e com observações feitas em mapas topográficos e geológicos. As unidades topográficas repetitivas na paisagem, associadas a um tipo particular de vegetação e litologia, que poderiam estar associados a determinados tipos de solos, foram agrupadas e legendadas. Este procedimento facilitou a identificação das primeiras unidades de mapeamento.

Com as informações da fotointerpretação, realizou-se um trabalho de campo com o fim de se fazer uma aferição da mesma, ou seja, conferir as unidades de mapeamento preestabelecidas e fazer as correlações destas com as diversas feições da paisagem. Esse procedimento foi de grande importância, pois permitiu verificar alguns aspectos importantes da paisagem não observados através da fotointerpretação.

Após o trabalho de campo, a fotointerpretação foi reavaliada, para que se pudesse incorporar as modificações observadas em campo. Desta forma, novas unidades de mapeamento foram estabelecidas, outras desapareceram e, ainda, outras foram modificadas, com o objetivo de se chegar a uma aproximação da realidade do campo. Após estes procedimentos foi possível elaborar a legenda preliminar, que serviu de guia para a identificação dos solos durante o mapeamento.

Foi realizado um terceiro trabalho de campo, que teve como objetivo a abertura de trincheiras e a descrição de solos (seguindo-se os procedimentos de Lemos e Santos, 1996), e a coleta de amostras. Nesta viagem foram definidos os limites de cada unidade de mapeamento.

O método de prospecção utilizado foi o de investigação ao longo de toposseqüências, EMBRAPA (1995), onde os solos e suas variações foram correlacionados com as superfícies geomorfológicas em que ocorrem - alta, média e baixa vertente, onde ocorriam as maiores rupturas de declive. Foram descritos e analisados 29 perfis, sendo coletadas 91 amostras. Os pontos de amostragem apresentam-se concentrados porque escolheu-se, de antemão, a alta bacia do Ribeirão Chiqueiro. Os perfis descritos e analisados contemplaram toda a heterogeneidade da área observada através da fotointerpretação e trabalhos de campo (Figura 2).

A descrição e coleta dos solos foi feita concomitantemente com a coleta de outros dados: posição do perfil e declividade da vertente (coletada através de clinômetros e balizas); altitude e coordenadas geográficas (coletadas por GPS); uso do solo; erosão; vegetação; localização e relevo.

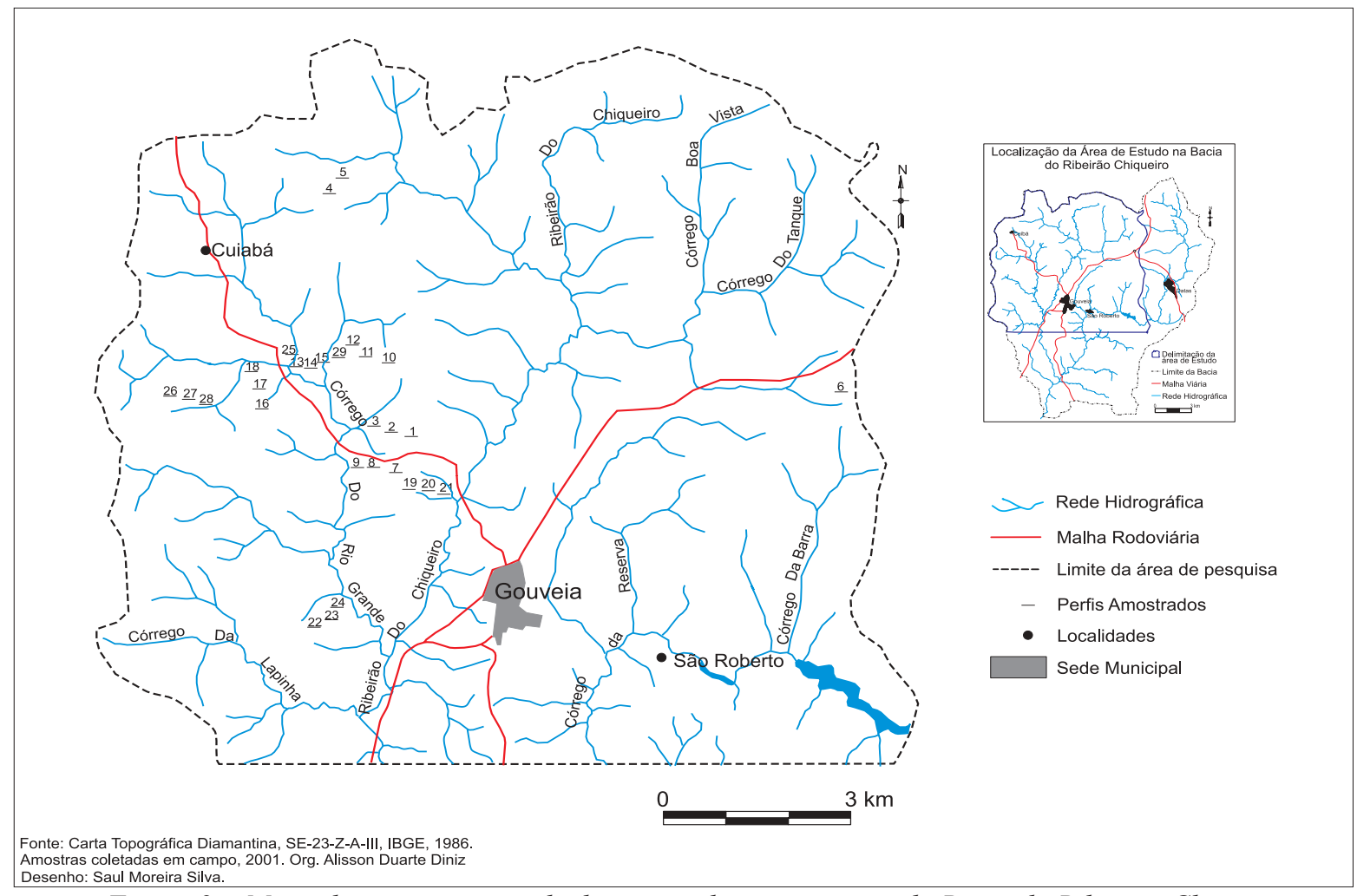

Figura 2 - Mapa de amostragem e de drenagem da porção norte da Bacia do Ribeirão Chiqueiro. 
Após a descrição e coleta dos solos, as amostras foram enviadas para laboratório - Embrapa Milho e Sorgo (Sete Lagoas) onde foram realizadas as análises físicas (granulometria e argila natural) e químicas (fertilidade), segundo EMBRAPA (1997).

Com os dados de laboratório e de campo foi possível elaborar o mapa de solos, substituindo as unidades fisiográficas de mapeamento preestabelecidas pela fotointerpretação e trabalhos de campo, por unidades de mapeamento de solos. Nesta etapa, foi produzido um mapa de declividade a partir do mapa topográfico de 1:100.000 da Folha de Diamantina, que auxiliou na elaboração do mapeamento pedológico. Foi realizado um último trabalho de campo para acerto final da legenda e confirmação das unidades de mapeamento, sendo estabelecido, assim, o mapa pedológico definitivo.

\section{RESULTADOS E DISCUSSÃO}

Os solos da região de estudo foram classificados de acordo com a Classificação Brasileira de Solos (EMBRAPA, 1999). Segundo esse sistema, os solos podem ser agrupados em seis níveis categóricos: $1^{\circ}$ nível (ordens), $2^{\circ}$ nível (subordens), $3^{\circ}$ nível (grandes grupos), $4^{\circ}$ nível (subgrupos), $5^{\circ}$ nível (famílias) e $6^{\circ}$ nível (séries), sendo que atualmente o sistema classifica-os até o quarto nível categórico. Tomando-se como base esses quatro níveis, foram encontrados, na área estudada, os solos apresentados na Figura 3.

Os solos estudados desenvolveram-se em função da combinação entre os diferentes materiais de origem e formas de relevo, demostrando, em associação com outros aspectos do ambiente, diferenças na paisagem (Tabela 1).

TABELA 1 - Características ambientais das classes de solos da região de estudo.

\begin{tabular}{|c|c|c|c|c|c|c|c|}
\hline $\begin{array}{c}\text { Classes de } \\
\text { Solos }\end{array}$ & Relevo & $\begin{array}{l}\text { Formação } \\
\text { Geológica }\end{array}$ & Litologia & Posição & Vertente & $\begin{array}{c}\text { Área } \\
(\%)\end{array}$ & Vegetação \\
\hline $\begin{array}{l}\text { Latossolos } \\
\text { Vermelhos }\end{array}$ & $\begin{array}{l}\text { Suave } \\
\text { ondulado e } \\
\text { ondulado }\end{array}$ & $\begin{array}{l}\text { Diques e } \\
\text { Soleiras de } \\
\text { Metabásicas }\end{array}$ & $\begin{array}{l}\text { Rochas } \\
\text { Metabásicas }\end{array}$ & $\begin{array}{l}\text { Alta, } \\
\text { média e } \\
\text { baixa } \\
\text { vertente }\end{array}$ & $\begin{array}{l}\text { Convexa- } \\
\text { retilínea } \\
\text { convexo- } \\
\text { convexas }\end{array}$ & 23 & $\begin{array}{l}\text { Floresta } \\
\text { Tropical } \\
\text { Subcaducifólia }\end{array}$ \\
\hline $\begin{array}{l}\text { Latossolos } \\
\text { Vermelho - } \\
\text { Amarelos }\end{array}$ & $\begin{array}{l}\text { Suave } \\
\text { ondulado e } \\
\text { ondulado }\end{array}$ & $\begin{array}{l}\text { Complexo } \\
\text { Gouveia }\end{array}$ & $\begin{array}{l}\text { Granito, } \\
\text { aflorando, } \\
\text { localmente, } \\
\text { gnaisses e/ } \\
\text { ou } \\
\text { migmatitos }\end{array}$ & $\begin{array}{l}\text { Alta e } \\
\text { média } \\
\text { vertente }\end{array}$ & $\begin{array}{l}\text { Convexa- } \\
\text { retilínea }\end{array}$ & 10 & Cerrado \\
\hline $\begin{array}{l}\text { Cambissolos } \\
\text { Háplicos }\end{array}$ & $\begin{array}{l}\text { Ondulado e } \\
\text { forte } \\
\text { ondulado }\end{array}$ & $\begin{array}{l}\text { Complexo } \\
\text { Gouveia }\end{array}$ & $\begin{array}{l}\text { Granito, } \\
\text { aflorando, } \\
\text { localmente, } \\
\text { gnaisses e/ } \\
\text { ou } \\
\text { migmatitos }\end{array}$ & $\begin{array}{l}\text { Alta, } \\
\text { média e } \\
\text { baixa } \\
\text { vertente }\end{array}$ & $\begin{array}{l}\text { Convexo- } \\
\text { convexas }\end{array}$ & 19 & $\begin{array}{l}\text { Cerrado, } \\
\text { Campo Sujo }\end{array}$ \\
\hline $\begin{array}{l}\text { Neossolos } \\
\text { Litólicos }\end{array}$ & $\begin{array}{l}\text { Plano, } \\
\text { ondulado, } \\
\text { forte } \\
\text { ondulado e } \\
\text { montanhoso }\end{array}$ & $\begin{array}{l}\text { Grupo Costa } \\
\text { Sena; } \\
\text { Formação } \\
\text { São João da } \\
\text { Chapada, } \\
\text { Sopa } \\
\text { Brumadinho } \\
\text { e Galho do } \\
\text { Miguel. }\end{array}$ & $\begin{array}{l}\text { Quartzo - } \\
\text { xisto, quartzo } \\
\text { - mica xistos, } \\
\text { clorita - } \\
\text { quartzo - } \\
\text { xistos e } \\
\text { quartzitos }\end{array}$ & $\begin{array}{l}\text { Alta, } \\
\text { média e } \\
\text { baixa } \\
\text { vertente }\end{array}$ & $\begin{array}{c}\text { Cristas } \\
\text { monoclinais } \\
\text { Escarpas } \\
\text { Colinas } \\
\text { tabulares }\end{array}$ & 26 & $\begin{array}{l}\text { Campo } \\
\text { Rupestre, } \\
\text { Campo de } \\
\text { Altitude e } \\
\text { Campo Limpo }\end{array}$ \\
\hline $\begin{array}{l}\text { Neossolos } \\
\text { Flúvicos }\end{array}$ & Plano & $\begin{array}{l}\text { Depósitos } \\
\text { Aluvionares }\end{array}$ & $\begin{array}{l}\text { Areias } \\
\text { variadas, } \\
\text { cascalhos } \\
\text { finos a } \\
\text { grosseiros e } \\
\text { turfeiras } \\
\text { arenosas. }\end{array}$ & Terraço & - & 3 & $\begin{array}{l}\text { Mata de } \\
\text { Galeria, } \\
\text { Estrato } \\
\text { Herbáceo }\end{array}$ \\
\hline
\end{tabular}




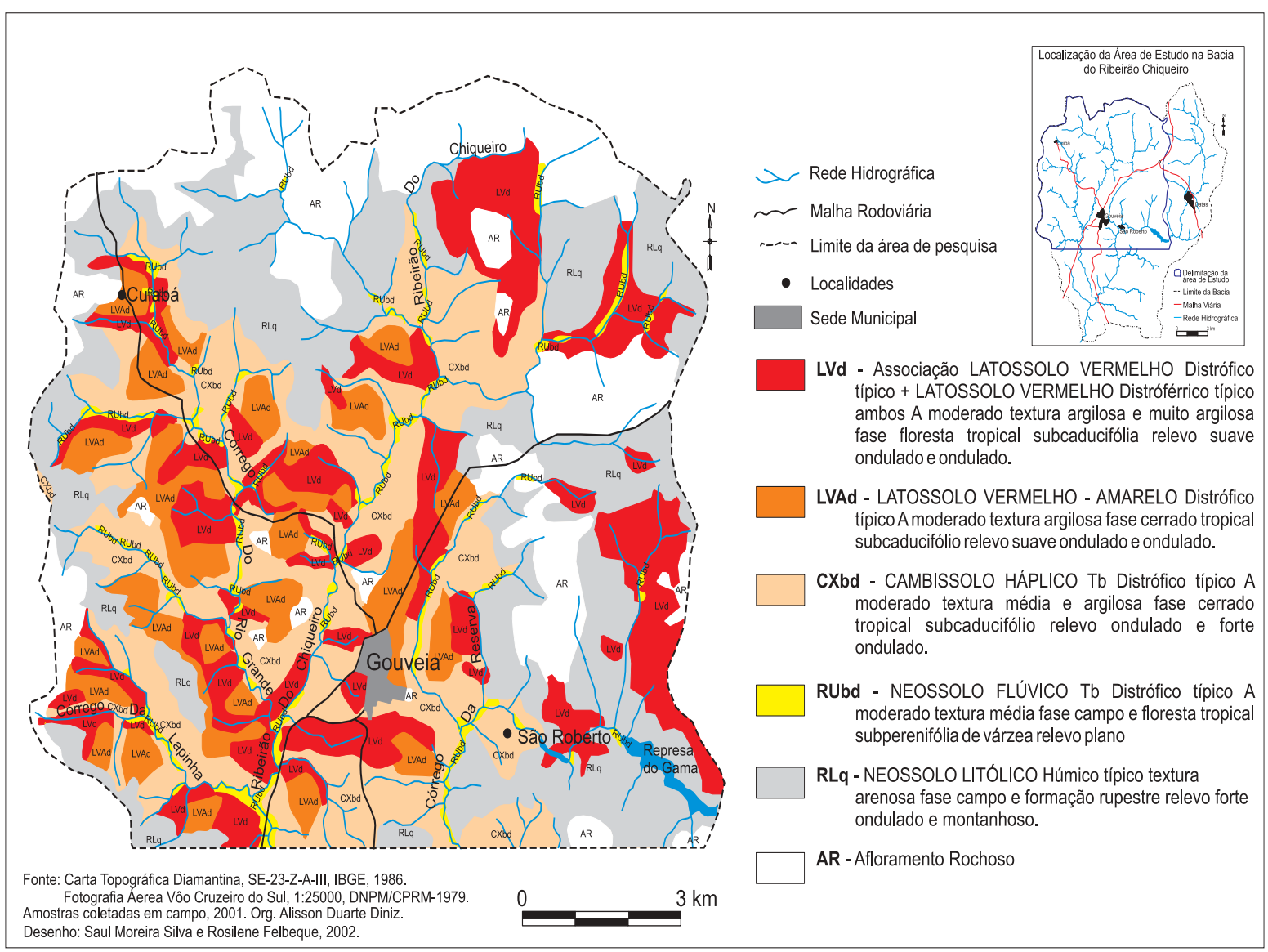

Figura 3- Mapa Pedológico da Porção Norte da Bacia do Ribeirão Chiqueiro

O desenvolvimento dos Latossolos Vermelho-Amarelos distróficos (LVAd) na região de estudo está relacionado, principalmente, às rochas graníticas e às superfícies de menores declividades, variando entre 4,0 e 7,0 graus, em relevo convexo - retilíneo, apresentando vertentes mais extensas e uniformes. Nas superfícies onde estes solos ocorrem, observou-se que da média para a baixa vertente há uma tendência ao rejuvenescimento dos mesmos, em razão do aumento da declividade. Portanto, os Latossolos Vermelho - Amarelos, com grande profundidade (horizonte Bw com mais de $100 \mathrm{~cm}$ ), estão associados às porções alta e média da vertente, com superfícies mais regulares, estando a parte baixa da vertente relacionada aos Cambissolos ou, quando sobre rochas metabásicas, Latossolos Vermelhos (Tabela $1 \mathrm{e}$ 2 e Figura 4).

Estes solos apresentam-se argilosos e a argila possui alto grau de floculação, chegando a $93 \% \mathrm{em}$ alguns horizontes Bw, evidenciando, assim, o processo de latossolização, responsável pela grande remoção de sílica e bases e um relativo incremento de óxidos de ferro e de alumínio, gerando no solo a estrutura granular muito pequena.

Tabela 2 - Relação solos, litologia e declividade de vertente localizada próximo à confluência dos córregos Gameleira e Grande.

\begin{tabular}{|c|c|c|c|c|c|}
\hline Perfil & $\begin{array}{c}\text { Distância } \\
\text { da Vertente (m) }\end{array}$ & Ângulo & Litologia & $\begin{array}{c}\text { Posição } \\
\text { Vertente }\end{array}$ & $\begin{array}{c}\text { Classe de } \\
\text { Solo }\end{array}$ \\
\hline & 20 & 3,5 & & & \\
\hline & 40 & 4 & & & \\
\hline & 60 & 4 & & & \\
\hline Perfil 1 & $\mathbf{8 0}$ & $\mathbf{6}$ & Granito & Alta & LVAd \\
\hline & 100 & 5,5 & & & \\
\hline & 120 & 6 & & & \\
\hline & 140 & 6,25 & & & \\
\hline & 160 & 6 & & & \\
\hline & 180 & 7 & & & \\
\hline & 200 & 7 & & & \\
\hline
\end{tabular}


Tabela 2 - Relação solos, litologia e declividade de vertente localizada próximo à confluência dos córregos Gameleira e Grande.

\begin{tabular}{|l|c|c|c|c|c|}
\hline Perfil 2 & $\mathbf{2 2 0}$ & $\mathbf{6 , 5}$ & Granito & Média & LVAd \\
\hline & 240 & 6 & & & \\
\hline & 260 & 6,5 & & & \\
\hline & 280 & 7 & & & \\
\hline & 300 & 6,5 & & & \\
\hline & 320 & 10 & & & \\
\hline & 340 & 10 & & & \\
\hline & 360 & 4 & & & \\
\hline Perfil 3 & $\mathbf{3 8 0}$ & $\mathbf{5 , 5}$ & Metabásica & Baixa & LVd \\
\hline & 400 & 7 & & & \\
\hline & 410 & 8,5 & & & \\
\hline
\end{tabular}

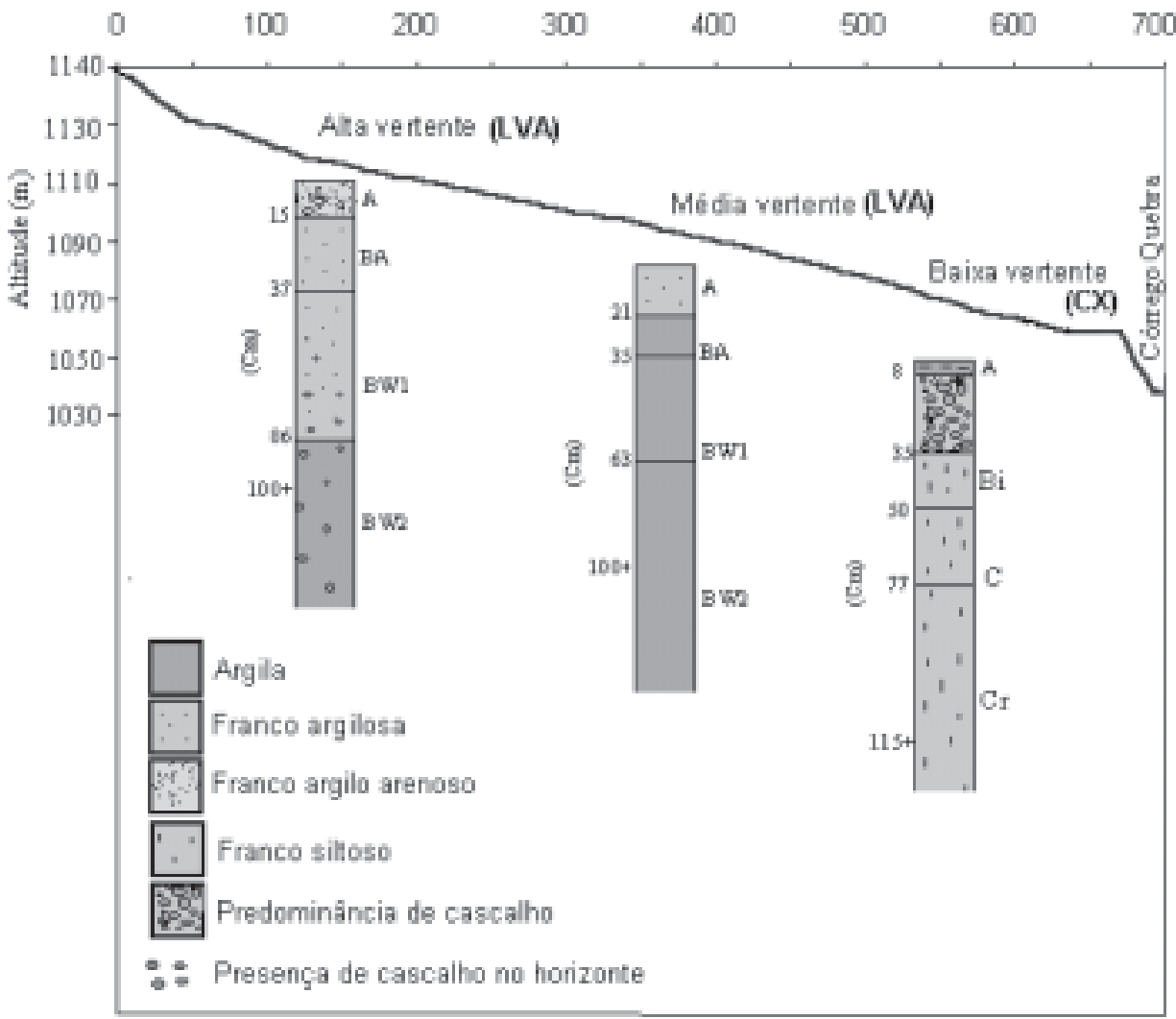

Figura 4 - vertente representando Latossolos Vermelho - Amarelos e Cambissolos

O desenvolvimento dos Latossolos Vermelhos distróficos $(\mathrm{LVd})$ da região está relacionado diretamente ao material de origem (rochas metabásicas de fácil intemperismo) e às superfícies em que se encontram. Estão associados ao relevo suave ondulado, em vertentes convexo - retilíneas, de maior extensão e uniformidade (o que lhe proporciona maior desenvolvimento) e ao relevo ondulado, em vertentes convexo - convexas, com predomínio dos primeiros. As posições no relevo que esses solos ocupam são, indistintamente, alta, média e baixa vertente, podendo a última ter uma freqüência maior - Tabela 1 e Figura 5. São muito comuns, também, em fundo de vales. Em razão da grande susceptibilidade das rochas metabásicas à alteração química, apresentamse profundos e são rapidamente explorados pela erosão concentrada, favorecendo a formação de ravinamentos e drenagens de ordens superiores.

A ocorrência desse espesso manto de alteração, associado aos latossolos da região, aponta, também, para o fato de que parece ter prevalecido um clima quente $\mathrm{e}$ úmido durante um longo período, favorecendo a atuação de processos de intemperismo químico. Portanto esses solos são caracterizados, principalmente, pela sua profundidade e pouca diferenciação entre horizontes (Figura 5). 


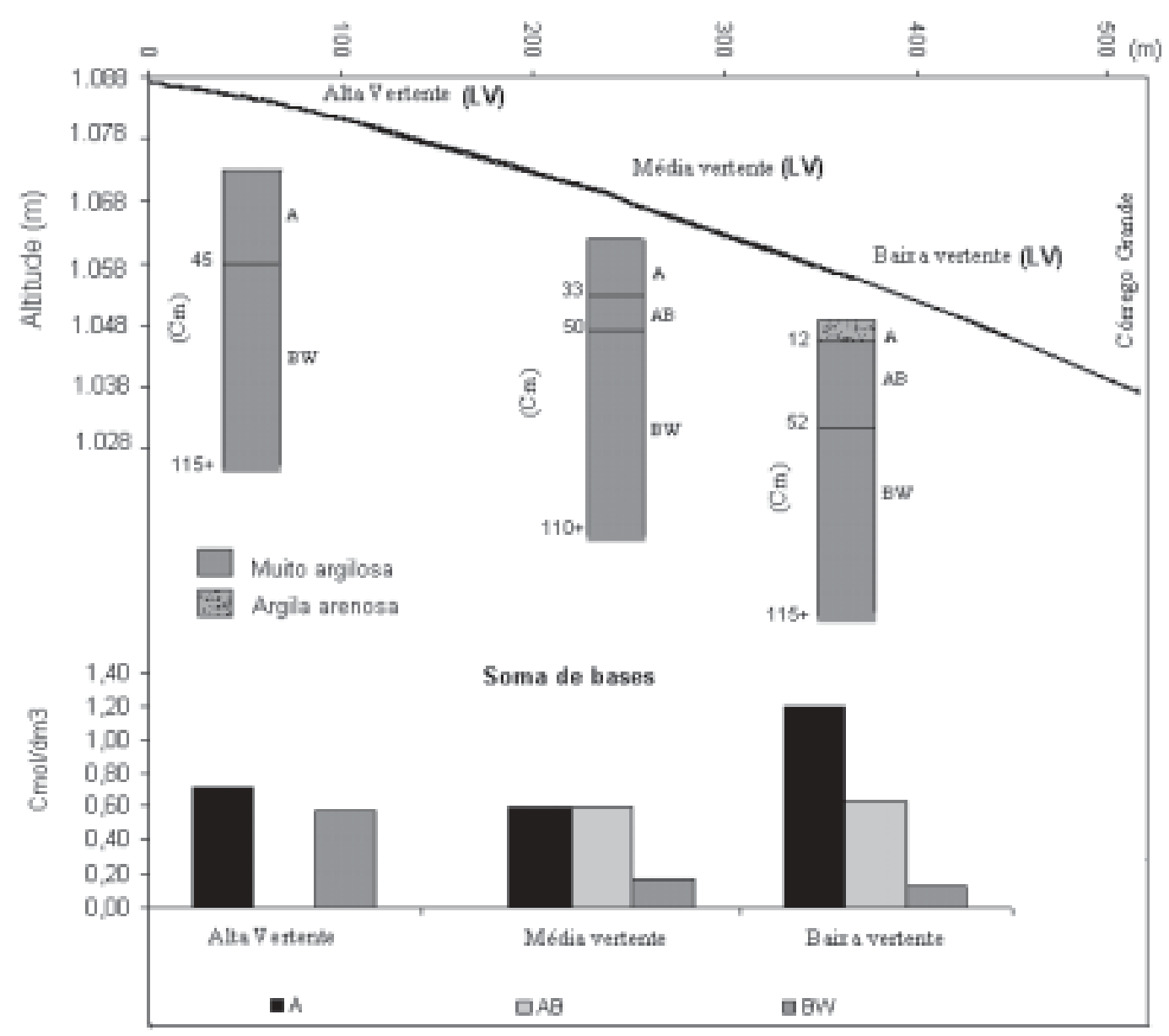

Figura 5 - Esquema representativo de vertente com Latossolos Vermelhos

Nestes Latossolos desenvolveu-se uma mata, atualmente muito degradada pela atividade antrópica. Essa vegetação está associada à presença de maiores quantidades de nutrientes e umidade destes solos (em relação aos outros), uma vez que está localizada em locais predominantemente de "hollows", anfiteatros e vales, receptores de água e nutrientes (Figura 5). A rocha de origem também responde pela maior presença de bases nestes solos, apesar de encontrarem-se lixiviados e com capacidade de troca catiônica relativamente baixa, pouco superior às demais classes da área.

O grande desenvolvimento desses solos proporcionou, da mesma forma, o desenvolvimento de sua estrutura. Em relação a esta característica, praticamente todos os perfis apresentam horizontes com estrutura granular, típico dos solos que sofreram o processo de latossolização. No caso dessa classe, a formação desse tipo de estrutura foi também bastante influenciada pelos maiores teores de ferro e matéria orgânica, além dos maiores teores de gibbsita que ela possui, segundo dados mineralógicos apresentados por Figueiredo (1999) e Ádamo (2001).

A estrutura granular desses solos, associada ao alto grau de floculação da argila, proporciona, assim, boas características físicas que favorecem a drenagem interna e a aeração (também relacionada às cores mais avermelhadas do perfil), o que propicia ótimas condições à penetração e desenvolvimento do sistema radicular das plantas (Baruqui, 1983).
O desenvolvimento dos Cambissolos Háplicos (CXbd) em Gouveia está relacionado, principalmente, com a morfologia do terreno associado a litologia (Tabela 1). A forma do relevo, assim como a declividade, em torno de $12^{\circ}$, é o aspecto primordial no desenvolvimento desses solos na região focalizada. Sendo assim, a forma convexo - convexa com vertentes curtas (em média 200m) e as zonas de baixa vertente das vertentes convexo retilíneas, onde estão as maiores declividades, são fortemente associadas a esta classe de solos (Figura 6).

Como a forma do relevo e a declividade, aliadas à litologia (granito), não permitiram uma maior evolução pedogenética nesta classe, levando a um estágio incipiente de desenvolvimento, esses solos ficam em posição superior de evolução pedológica da região apenas em relação aos Neossolos. Desta forma, esta classe apresenta horizonte B incipiente (Bi), demostrando menor grau de alteração físico - química, porém, suficiente para o desenvolvimento de cor e estrutura (EMBRAPA, 1999).

Em vista disso, o horizonte Bi apresenta pequena espessura, a maioria não ultrapassando $30 \mathrm{~cm}$. Como grande parte dos horizontes A possuem espessuras ainda menores, variando entre 8 e $12 \mathrm{~cm}$ (em alguns não sendo possível nem a sua descrição devido a presença de muito cascalho), nota-se que o solum (Horizontes A e B) é pouco espesso. 
O pequeno desenvolvimento deste solo repercute nas suas características texturais e estruturais. Em razão disso, a descrição morfológica dos perfis apresenta horizontes $\mathrm{Bi}, \mathrm{C}$ e $\mathrm{Cr}$ com estrutura em blocos moderada e fraca a moderada e horizontes $\mathrm{C}$ e $\mathrm{Cr}$ com estrutura maciça. Em muitas observações foi possível verificar a existência da estrutura da rocha no horizonte C, entremeada no aspecto maciço deste horizonte. No horizonte A observa-se a ocorrência da estrutura granular devido aos maiores teores de matéria orgânica e maior pedoturbação. A característica desses horizontes $\mathrm{B}$, associados ao horizonte $\mathrm{C}$ profundo, mostram que esta é uma região em processo de rejuvenescimento acelerado dos solos e, portanto, muito susceptível ao voçorocamento.

Os dados granulométricos atestam a maior proximidade deste solo com a rocha de origem e o seu menor grau de desenvolvimento, pois em profundidade, os teores de argila diminuem e os de silte e areia, principalmente a fina, aumentam, mostrando, assim, maior proximidade com o material de origem (Figura 6).
Em termos de evolução pedogenética, os Neossolos são os solos de menor desenvolvimento na região de estudo, possuindo horizonte $\mathrm{A}$ e, subjacente a este, o horizonte ou camada $\mathrm{C}$, destituído de horizonte B diagnóstico. Os Neossolos Litólicos (RLq) estão em áreas de maiores altitudes, em média 1.400 metros. Ocorrem tanto em áreas de forte declividade, em torno de 27 graus, em relevo montanhoso, de cristas monoclinais, como em áreas de baixa declividade, em relevos mais planos ou de colinas tabulares em relevos estruturais. A presença destes solos está associada, principalmente, ao conjunto de rochas: quartzo - xisto; quartzo - mica xistos; clorita - quartzo - xistos e quartzitos (tabela 1). A forte declividade ou mesmo o relevo plano, mas apresentando rochas resistentes ao intemperismo, além do clima mais frio, o que inibe a atividade biológica e o intemperismo químico, proporcionou o pouco desenvolvimento dos solos nestas áreas. Os Neossolos Flúvicos (RUbd) estão associados às regiões de terraços, onde a natureza deposicional recente de sedimentos retarda a evolução desse solo.

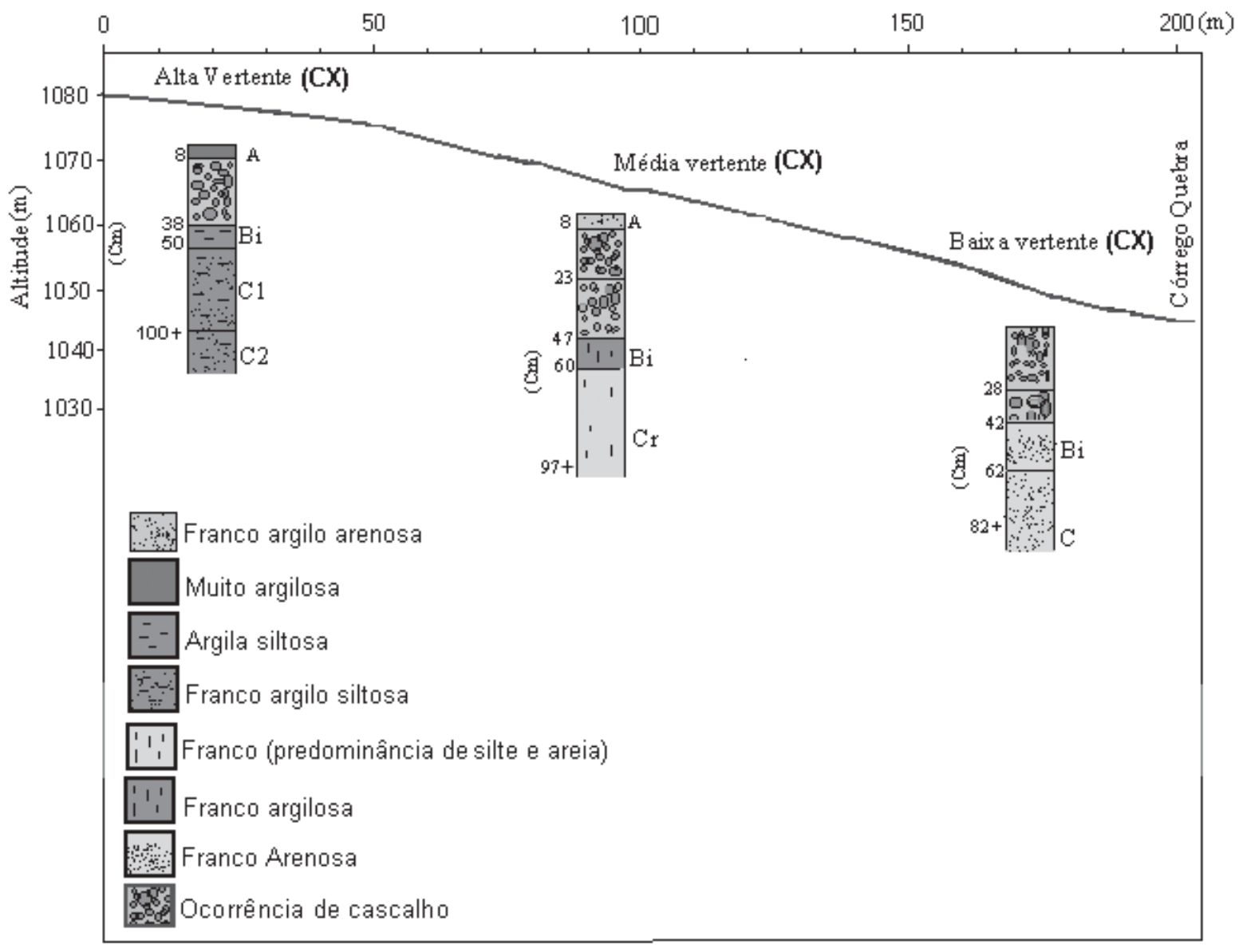

Figura 6-Cambissolo em vertente convexa convexo curta 


\section{CONSIDERAÇÕES FINAIS}

O relevo exerce um papel primordial na distribuição dos solos da Bacia do Ribeirão Chiqueiro. Nos trechos medianos e elevados das vertentes de colinas convexas retilíneas, ou mais regulares, desenvolveram-se Latossolos Vermelho - Amarelos. Por outro lado, quando a convexidade aumenta, especialmente nas vertentes baixas de colinas convexo - convexas, tornando a vertente mais declivosa, predominam Cambissolos mais rasos e menos intemperizados.

A litologia também se destaca na formação dos solos da região. Em áreas de ocorrência das rochas metabásicas verificam-se os Latossolos Vermelhos, que se caracterizam por serem bem desenvolvidos e apresentam, juntamente com os Neossolos Flúvicos, maior riqueza em nutrientes, apesar de distróficos.

Nas regiões de elevadas declividades, de cristas monoclinais, e nas áreas de colinas tabulares, com litologia predominante de quartzo - xisto, quartzo - mica xistos, clorita - quartzo - xistos e quartzitos, desenvolveram-se os Neossolos Litólicos. A maior resistência dessas rochas, a alta declividade ou o clima mais frio foram fatores decisivos para o pouco desenvolvimento desses solos. Nos terraços ocorre outra classe que, devido à dinâmica fluvial, apresenta pouco desenvolvimento: os Neossolos Flúvicos, que possuem camadas estratificadas e intercaladas de areia grossa e areia fina, com ocorrência de cascalho entre algumas dessas camadas.

\section{AGRADECIMENTOS}

- Ao Dr. Paulo Roberto Antunes Aranha - Depto de Geologia - IGC - UFMG

- Ao Dr. João Carlos Ker - Departamento de Solos - UFV

- Dr. Luiz Marcelo Sanz da EMBRAPA Milho e Sorgo (Sete Lagoas)

- À FAPEMIG e ao FINEP pelo financiamento do projeto.

\section{REFERÊNCIAS BIBLIOGRÁFICAS}

ÁDAMO, R. Caracterização hidrológica da zona não-saturada do solo em 3 vertentes localizadas na bacia do ribeirão do Chiqueiro, Gouveia, MG, serra do Espinhaço meridional. Belo Horizonte: IGC/UFMG, 2001. 139 p. (Dissertação de Mestrado).

ALMEIDA-ABREU, P. A.. Geologia das quadrículas Onça e Cuiabá (Gouveia - MG), Região Mediana Central da Serra do Espinhaço Meridional. Dissertação de Mestrado, Departamento de Geologia, Universidade do Rio de Janeiro, Rio de Janeiro, 1989.

ALMEIDA-ABREU, P. A.. Universidade Federal de Minas Gerais UFMG (Belo Horizonte); Centro de Geologia Eschwege (Diamantina) (Belo Horizonte). Mapa Geológico da Quadrícula Cuiabá, Gouveia, Minas Gerais, Brasil. Belo Horizonte, 1985. Mapa Geológico. Escala 1:25.000.
AUGUSTIN, C.H.R.R. Geoökologische Studien im Südlichen Espinhaço Gebirge bei Gouveia, Minas Gerais, Brasilien Unter Besonderer Beucksichtigung der Landschaftsentwicklung. Tese de Doutorado: 147 p. Universidade de Frankfurt, Frankfurt, Alemanha, 1995.

AUGUSTIN, C.H.R.R.. Tropical landscape evolution: weathering and erosion processes in Gouveia, Minas Gerais, Brasil. In: Regional Conference on Geomorphology - The Brazilian Geomorphological Union (UGB). Abstracts. Rio de Janeiro RJ. p. 67.1999.

BARUQUI, A. M. Comentários sobre a descrição e resultados analíticos de um perfil de solo. Informe Agropecuário, Belo Horizonte, v.9, $n^{\circ}$ 105, $33-44,1983$.

BIRKELAND, P. W. Pedology, weathering and geomorphological research. New York: Oxford University, 1974. 285p.

BIRKELAND, P. W. Soils and Geomorphology. New York: Oxford University, 1984. 372p.

CHRISTIAN, C.S.; STEWART, G. A. Methodology of integrated surveys. In: aerial surveys and integrated studies. Proceedings of the Toulouse Conference. UNESCO, 1968. p. 233-277.

COMIG (Companhia Mineradora de Minas Gerais) e UFMG (Universidade Federal de Minas Gerais). Belo Horizonte - MG, 1996. Mapa Geológico da Folha Diamantina, Minas Gerais, Brasil. Escala 1:100.000

EMBRAPA - EMPRESA BRASILEIRA DE PESQUISA AGROPECUÁRIA. Centro Nacional de Pesquisa de Solos. Manual de métodos de análise de solo. Rio de Janeiro, 1997. 212p.

EMBRAPA - EMPRESA BRASILEIRA DE PESQUISA AGROPECUÁRIA. Procedimentos normativos de levantamentos pedológicos, Brasília, EMBRAPA - CNPS - SPI, 1995. 116p.

EMBRAPA - EMPRESA BRASILEIRA DE PESQUISA AGROPECUÁRIA. Sistema brasileiro de classificação de solos. Brasília: Serviço de Produção de Informação; Rio de Janeiro: Embrapa Solos, 1999. 395p.

FIGUEIREDO, M. A.. Óxidos de ferro pedogênicos e sua influência na agregação de partículas de argila: estudo de caso nos solos da região de Gouveia - Serra do Espinhaço Meridional - MG. 1999. 95p. Dissertação (Mestrado) - Instituto de Geociências, Universidade Federal de Minas Gerais, Belo Horizonte.

IBGE - Instituto Brasileiro de Geografia e Estatística. Mapa Topográfico de Diamantina, Minas Gerais, Brasil. Rio de Janeiro, 1986. Mapa Topográfico. Escala 1:100.000.

KOMAROV, V. B. Aerial photography in the investigation of natural resources in the USSR. In: Aerial surveys and integrated studies. Proceedings of the Toulouse Conference. UNESCO, 1968. p. 143-181.

LEMOS, R.C.; SANTOS R.D. Manual de descrição e coleta de solo no campo. SBCS - CNPS. 3 ed. Campinas, 1996. 83p.

NIMER, E. 1989. Climatologia do Brasil. IBGE. Rio de Janeiro, $421 \mathrm{p}$.

PORTILHO, S. Padrões de infiltração e percolação da água no solo em vertente do Córrego do Quebra, Gouveia, MG, Espinhaço Meridional. 76p (Monografia) - Instituto de Geociências, Universidade Federal de Minas Gerais, Belo Horizonte, 2000.

RUHE, R. V. Geomorphology. Boston : Houghton Mifflin, 1975. $246 \mathrm{p}$.

SAADI, A.; VALADÃO. R.C. Evolução morfodinâmica Quaternária da região de Gouveia, Serra do Espinhaço - MG. Anais do $4^{\circ}$ Simpósio de Geologia de Minas Gerais, Belo Horizonte. 434448, 1987.

VINK, A . P. A . Aerial photographs and the soil sciences. In: Aerial surveys and integrated studies. Proceedings of the Toulouse Conference. UNESCO, 1968. p. 81-136

WRIGHT, R. L. Principles in a Geomorphological Approach to Land Classification. Z. Geomorph. 16, p. 351-373. 1972.

WRIGHT, R. L. An Examination of site analysis in field studies in tropical Australia. Z. Geomorph., 17, p. 157-183. 1973. 